\title{
TRANSFORMAÇÕES GEOMORFOLÓGICAS NA BACIA HIDROGRÁFICA DO RIBEIRÃO DOS BURROS (JUIZ DE FORA/MG)
}

\author{
GEOMORPHOLOGICAL TRANSFORMATIONS IN THE RIBEIRÃO DOS \\ BURROS WATERSHED (JUIZ DE FORA/MG, BRAZIL)
}

\section{LES TRANSFORMATIONS GEOMORPHOLOGIQUES DANS LE BASSIN HYDROGRAPHIQUE RIBEIRÃO DOS BURROS (JUIZ DE FORA/MG, BRÉSIL)}

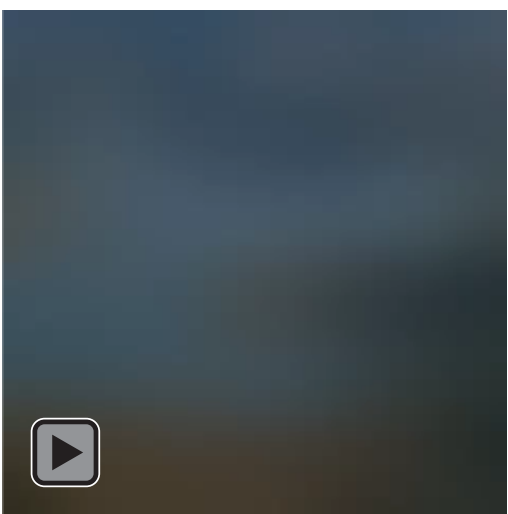

\section{Carolina Campos Eduardo}

Doutoranda no Programa de Pós-Graduação de Geografia da Universidade Federal do Rio de Janeiro (UFRJ).E-mail: carolcampos13@gmail.com

\section{Telma Mendes da Silva}

Professora associada II da Universidade Federal do Rio de Janeiro (UFRJ).

E-mail:telmendes@globo.com

\section{Miguel Fernandes Felippe}

Professor adjunto da Universidade Federal de Juiz de Fora (UFJF).

E-mail:mffelippe@gmail.com

\section{Resumo}

Este artigo aborda as principais mudanças antropogênicas causadas, entre os anos de $1983 \mathrm{e}$ 2007, na bacia hidrográfica do Ribeirão dos Burros, que abrange parte do município de Juiz de Fora, em Minas Gerais. Este estudo está pautado na interpretação do processo de ocupação da terra nessa bacia hidrográfica, que tem a presença de um manancial de água importante para o município. Para tanto, foi efetuado um tratamento teórico da antropogeomorfologia pelo viés da cartografia retrospectiva/evolutiva, fazendo-se uma analogia entre morfologia original e antropogênica, baseada em técnicas de fotointerpretação. Associada ao estudo da cartografia evolutiva, a classificação para terrenos tecnogênicos foi abordada e aplicada de acordo com a literatura brasileira. Como resultados desta pesquisa, foram observados o avanço da ocupação residencial nas margens desse manancial, o descumprimento da legislação ambiental no que tange às áreas de preservação permanentes e a proliferação de feições antropogênicas na bacia hidrográfica do Ribeirão dos Burros.

Palavras-chave: cartografia retrospectiva, tecnógeno, antropogeomorfologia, Ribeirão dos Burros, Juiz de Fora/MG.

\footnotetext{
D
}

D D p.138-161, V.15, n.26, jan./mar. 2019. 


\section{Abstract}

This article approaches the main anthropogenic changes occurred, between 1983 and 2007, in the Ribeirão dos Burros watershed, which covers part of the city of Juiz de Fora, in Minas Gerais state (Brazil). This study was conducted based on the interpretation of the land occupation process in this watershed, which presents an important water source for the city. In order to do so, the anthropogeomorphology was given a theoretical treatment via retrospective/evolutive cartography, as well as by comparing the original and the anthropogenic morphologies based on photointerpretation techniques. The study of evolutive cartography was associated with the classification of technogenic grounds, applied according to the Brazilian literature available. As a result of this research, it was possible to observe the advance of residential occupation in the margins of the water source, the noncompliance of the environment legislation regarding the areas of permanent preservation, and the proliferation of anthropogenic features in the Ribeirão dos Burros watershed.

Keywords: retrospective cartography, technogenic, anthropogeomorphology, Ribeirão dos Burros, Juiz de Fora (MG/Brazil).

\section{Résumé}

Cet article traite des principaux changements anthropiques intervenus entre les années 1983 et 2007 dans le bassin hydrographique Ribeirão dos Burros, qui couvre une partie de la municipalité de Juiz de Fora, dans l'état de Minas Gerais (Brésil). Cette étude est basée sur l'interprétation du processus d'occupation de la terre dans ce bassin, qui présente une source d'eau importante pour la municipalité. Un traitement théorique de l'anthropogéomorphologie a été donné par le biais de la cartographie rétrospective/évolutive et il a été faite une analogie entre la morphologie originale et anthropique par techniques de photointerprétation. Associée à l'étude de la cartographie évolutive, la classification des terres technogènes a été approché et appliqué selon les études brésiliennes. En conséquence de cette recherche, il a été observé une augmentation de loccupation résidentielle au bord de la source d'eau, le non-respect de la législation environnementale en ce qui concerne les zones de préservation permanentes et la prolifération de caractéristiques anthropiques dans le bassin hydrographique Ribeirão dos Burros.

Mots-clés: cartographie rétrospective, technogénie, anthropogéomorphologie, Ribeirão dos Burros, Juiz de Fora (MG/Brésil). 


\section{Introdução}

As atividades desenvolvidas pelo homem no substrato físico natural e as transformações resultantes destas têm promovido reflexões acerca do ser humano como um agente geomorfológico, seja de forma direta ou indireta (PELOGGIA et al., 2014). A participação humana na conformação do relevo e sua ação na fisiografia e fisiologia das paisagens vêm ganhando notoriedade no corpo acadêmico, impulsionada por trabalhos que remontam ao início do século XX e se adensam a partir do pós-guerra (GERASIMOV, 1979; CHEMEKOV, 1983; TER-STEPANIAN, 1983).

Mudanças exercidas na paisagem, causadas pelos inúmeros cortes de terrenos para assentamentos residenciais, práticas de terraplanagem para instalação de indústrias, coberturas de estruturas viárias e mudanças de cursos d'água por técnicas de retificação, entre outras, são algumas tipificações capazes de alterar o sistema geomorfológico local, tanto em sua composição genética (modelados de agradação ou dissecação), quanto na desagregação dos materiais e na intensificação ou estagnação dos processos ocorridos (PASCHOAL, 2014). Esta mesma autora cita as obras de Marsh, Man and nature (1864), e de Shaller, Man and the Earth (1905), cujas temáticas estão voltadas para as ações de remoção da cobertura vegetal e dos processos erosivos correlatos a esta prática, como relevantes no tocante à concepção do homem como agente geomorfológico.

No escopo desta perspectiva de análise, se observa o quanto os recursos naturais têm sido explorados diante do crescimento das demandas da humanidade, intensificando as transformações no relevo por processos de urbanização, pelo uso extensivo e intensivo da cobertura pedológica para as atividades pecuárias e da agricultura e pela remoção de conjuntos florestais, além da consequente emissão de gases poluentes decorrentes destas atividades (CRUZTEN, STORMER, 2000). Os processos geomorfológicos associados à atividade antropogênica compreendem o campo das forças exógenas, dadas pela extinção da cobertura vegetacional pela agricultura ou por obras de engenharia e pelas intervenções hidrológicas (diques, construção de barragens, retificações de canais etc.), entre outras intervenções no ambiente (KERÉNYI, 2010).

Conforme aponta Douglas (1983), a expressiva densidade da urbanização acarreta preocupações com os níveis de circulação de energia, de água e de materiais no sistema geomorfológico alterado. Esse autor acrescenta que os efeitos da impermeabilização na superfície de escoamento, o desenvolvimento dos processos erosivos e de movimentos gravitacionais de massa em vertentes, as alterações nos canais fluviais e nas planícies de inundação e a formação/destruição de novas e antigas formas de relevo para distintos usos (represamentos, diques, passagens de dutos ou terraceamentos) podem ser considerados como os principais distúrbios no sistema geomorfológico.

D

D Devista da Associação Nacional de Pós-graduação e Pesquisa em Geografia (Anpege).

D D p.138-161, V.15, n.26, jan./mar. 2019. 
Entre os estudiosos que se voltam para os estudos geomorfológicos relacionados às atividades humanas, Brown (1971) contribui para a caracterização das ações em modelos diretos e indiretos. Para esse autor, as influências podem ser derivadas da ação humana proposital direta, que ocorre majoritariamente em áreas de desenvolvimento industrial e da construção civil, tipificadas por obras de engenharia que realizam escavações para a preparação da fundação de uma edificação, sendo o material removido aproveitado em aterramento de vales para a utilização em outras práticas. Já a ação direta incidental configura em uma influência caracterizada pela formação de novas formas no relevo provocada pela extração de minérios, de areias e cascalhos e pela mineração subterrânea, que são capazes de destruir a morfologia original do solo e de alterar o sistema geomorfológico.

Quanto à influência indireta do homem sobre o solo, Brown (1971) elenca, entre alguns elementos antrópicos, ações como: a construção de lagos e outras formas proficientes na alteração do movimento da crosta, o intemperismo provocado pela ação mecânica e química exercida com técnicas de escavação, aragem ou drenagem sobre os solos, o uso de fertilizantes interferindo na composição química dos solos e subsolos, os movimentos de massa ocorridos pela desestabilização de encostas/vertentes por processos de ocupação destas e as modificações nos canais fluviais, por retificações ou mudanças de seu curso natural, alterando o comportamento hidrogeológico de um sistema fluvial.

Ainda em sua proposição, Brown (1971) demonstra o quanto as ações humanas têm uma escala temporal mais acelerada em comparação ao tempo e à forma de atuação dos processos exógenos naturais. Assim, afirma que

\begin{abstract}
A água e o gelo promovem erosão hoje exatamente como faziam no Pleistoceno ou no Carbonífero. Mas o homem não demonstra essa uniformidade; surgiu muito recentemente na Terra, sendo geomorfologicamente significante há apenas 8.000 anos e, provavelmente, por um período muito mais curto. [...] mas o homem tem aumentado sua potencialidade geomorfológica onde quer que ele apareça para fazer qualquer coisa (BROWN, 1971, p. 14).
\end{abstract}

Kohler (2002) e Perez-Filho e Quaresma (2012) coadunam da ideia de as atividades humanas desestruturarem o balanço energético do relevo, configurando numa disjunção da escala espaçotemporal dos fatos geomorfológicos. Com isso, feições que ora seriam paulatinamente formadas por processos ditos naturais podem ser construídas em uma temporalidade acelerada, à revelia das condições originais da paisagem. Exemplos dessa nova dinâmica, em diversas magnitudes espaciais, já são apontados pela literatura (PEIXOTO et al., 2011; FELIPPE et al., 2014; VITORINO et al., 2016; BROWN et al., 2017).

Em sua perspectiva de análise, Szabó (2010) coloca o agente humano em relevância com os demais fatores de formação do relevo, embora sua atuação esteja ligada diretamente à intensidade 
de energia dispensada na transformação da paisagem. Assim, para o autor mencionado, as ações geomórficas implementadas pela sociedade provocam mudanças ambientais em distintos meios, englobando as atividades de mineração, industriais e de expansão urbana, as alterações de canais fluviais, a agricultura, o turismo e as atividades esportivas, sendo estas últimas um novo campo de estudos na geomorfologia antropogênica devido às alterações que estas atividades podem causar à topografia, seja pela retirada de grupos vegetacionais para a abertura de trilhas para pedrestres ou para veículos off-road ou pela instalação de campos esportivos, entre outros, conforme Dávid et al. (2010) tratam detalhadamente.

As consequências dessas transformações na paisagem também foram debatidas pela proposição de Nir (1983), ao trazer uma discussão da geomorfologia voltada para as práticas humanas em uma abordagem sequencial, em que os aspectos de cunho social e os aspectos morfológicos possam ser integrados numa escala de análise temporal. Desse modo, pela leitura de Nir (1983), é possível reconhecer a proposta de estágios de pré-perturbação, perturbação ativa e pós-perturbação, que foram, posteriormente, categorizados por Rodrigues (2005) e Luz (2015) como: (1) pré-perturbação - majoritamente, um estágio em que as feições de relevo apresentam a morfologia original, cujo sistema não foi alterado pelo homem; (2) perturbação ativa - referente ao estágio de exposição dos terrenos a efeitos exógenos ligados às atividades construtivas; e (3) pós-perturbação -período em que novas feições de relevo são estabelecidas e consolidadas pelas atividades do homem.

O reconhecimento dessas fases de transformação do terreno está associado ao contexto histórico do dimensionamento do impacto antrópico levado a efeito no sistema geomorfológico, conforme Toy e Hadley (1987) asseguram. Desse modo, a geomorfologia antrópica volta sua catalogação de métodos e de técnicas para pesquisas que se utilizem da cartografia histórica, por meio de plantas cadastrais, de imagens aéreas de diferentes datas de análises, de carta geotécnica e de carta de aptidão ao assentamento urbano e zoneamento urbano, entre outros documentos cartográficos habilitados para fornecer condições de recapitular a história de ocupação em determinado recorte espacial e temporal.

O município de Juiz de Fora, no estado de Minas Gerais, não é uma exceção, nesse cenário de amplificação das transformações humanas no relevo. Com ocupação urbana que remonta ao início do século XVIII, época da construção do Caminho Novo da Estrada Real (CORDOVIL, 2013), foi, sobretudo, a partir do processo de industrialização pelo qual esse município passou, no início do século XX, que as modificações no relevo se avolumaram. Com a expansão urbana das últimas décadas, típica das cidades médias do Sudeste brasileiro (GARCIA, NOGUEIRA, 2003), houve a dispersão da estrutura urbana pela periferia do centro antigo, atingindo, entre outras

D

D Devista da Associação Nacional de Pós-graduação e Pesquisa em Geografia (Anpege).

D D p.138-161, V.15, n.26, jan./mar. 2019. 
áreas, a bacia hidrográfica do Ribeirão dos Burros (BHRB), localizada em Juiz de Fora. Nesse contexto, o presente trabalho busca traçar um paralelo entre a morfologia original e as principais transformações antropogênicas efetivadas entre o período de 1983 a 2007, nessa bacia hidrográfica.

A identificação das transformações na BHRB se orientou pela análise de práticas humanas que afetaram direta e/ou indiretamente suas feições geomorfológicas, tanto pela investigação da evolução morfodinâmica, quanto pelo emprego da cartografia geomorfológica de detalhe, segundo a proposta de Rodrigues (2005).

Nos últimos anos, as áreas urbanas brasileiras têm sido estudadas pela antropogeomorfologia, por meio da apresentação das mudanças na paisagem em escala temporal, em períodos anteriores aos impactos ambientais do homem e posteriormente à sua ocupação. Assim, esta proposta metodológica concebe o campo das pesquisas voltadas para a cartografia retrospectiva e evolutiva dos fenômenos geográficos na organização espacial (RODRIGUES, 2005).

Pellogia et al. (2014), ao discutirem metodologias e técnicas de categorização da morfologia alterada, se alicerçaram nos trabalhos dos britânicos, dos soviéticos e dos europeus do leste. Nesse contexto, estes autores baseiam sua proposta inserindo os novos terrenos formados pelas ações diretas ou indiretas do homem por processos erosivos ou acumulativos ocorridos em terrenos naturais, conceituando-os em: terreno tecnogênico de agradação e/ou de degradação, terreno tecnogênico modificado e terreno tecnogênico misto.

Os terrenos tecnogênicos de agradação e/ou degradação correspondem ao substrato geológico gerado, de forma direta ou indireta, pelas ações de acumulação ou remoção de material, tipificando os aterros, os bota-fora, os depósitos de lixo, os sulcos, as ravinas ou as voçorocas. Por sua vez, os terrenos tecnogênicos modificados são referentes aos horizontes alterados in situ pela contaminação de solos por pesticidas ou pela compactação de solos pela agricultura. Já os terrenos tecnogênicos mistos são identificados como resultantes da superposição das ações antrópicas, por aterros construídos sobre depósitos de assoreamento induzidos ou sobre horizontes de solo tecnogênico e aterro modificadado pelos efluentes (PELLOGIA et al., 2014).

\section{Metodologia}

Os mapas de geomorfologia basilares para a interpretação das feições de relevo adotados neste artigo foram produzidos por Marques Neto et al. (2017) e Eduardo (2018) para o município de Juiz de Fora, na escala 1:50.000, nos quais foram apresentadas as tipologias genéticas agradacionais (A), dadas pelas planícies, os modelados de dissecação homogênea (D), tipificados por colinas, morros e morrotes, e de dissecação em controle estrutural (DE), representados pelas serras e cristas. 
Por sua vez, para levar a efeito os levantamentos das informações necessárias para os anos analisados, foram utilizadas as imagens aéreas disponíveis. Para a identificação da morfologia original (fase de pré-perturbação), foi utilizada a imagem do voo aéreo de 1983, em preto e branco, na escala de 1:10.000, fornecida pela Prefeitura de Juiz de Fora (PJF). No estágio de pósperturbação (processos ocorridos), foi utilizada a cobertura aerofotogramétrica do ano de 2007, com resolução espacial de 20 centímetros.

A organização do banco de dados foi realizada a partir do Sistema de Informação Geográfica (SIG), operacionalizado por meio do software ArcGIS, com o uso da ferramenta de zoom escalar e pela fotointerpretação. As observações das imagens por meio da técnica de fotointerpretação tornaram possíveis a identificação das feições geomórficas, pela diferenciação das variações de cores em feições de relevo alteradas e comparadas e dos desníveis topográficos devido aos cortes no terreno para a implantação de loteamentos e abertura de vias de acesso, e a diferenciação da morfologia de paisagens adjacentes, conforme Peixoto et al. (2011) aplicaram também em sua pesquisa. Esta diferenciação de morfologias foi registrada pela observação das imagens de 2007 que não estavam presentes na imagem de 1983, com a representação gráfica dada pela vetorização de manchas poligonais das feições do tipo meandros abandonados e de loteamentos residenciais, enquanto as retificações nos cursos fluviais foram representadas por feições de linhas e a indicação de processos erosivos representada por pontos. Sendo assim, estas feições foram consideradas como novas morfologias na paisagem.

\section{Área de estudo}

A bacia hidrográfica do Ribeirão dos Burros está adstrita ao perímetro urbano, na zona norte de Juiz de Fora, com área aproximada de $71,92 \mathrm{~km}^{2}$, pertencendo à bacia do rio Paraibuna. Os principais cursos hídricos da BHRB abrangem o Ribeirão dos Burros e os córregos Remonta, Vista Alegre, Palmeira e Vargem Grande.

A classificação florestal existente é interpretada como floresta estacional semidecidual submontana (IBGE, 1992), profundamente alterada por culturas históricas, apresentando-se como ilhas de vegetação secundária na paisagem, na maioria das vezes, originadas por sucessão espontânea. Sob estas ilhas de vegetação, ocorrem as unidades de cobertura pedológicas definidas, predominantemente, como latossolos vermelho-amarelo distrófico (LVAd59) e uma pequena faixa de latossolo amarelo (LAd4) (Mapa de solos do Estado de Minas Gerais, na escala de 1:600.000, Fundação Estadual do Meio Ambiente/FEAM, 2010). Localmente, é possível identificar, com frequência, a ocorrência de argissolos, associados à translocação de argila no perfil de vertentes de média declividade, e de cambissolos, relacionados ao rejuvenescimento por decapeamento dos

D

D D Revista da Associação Nacional de Pós-graduação e Pesquisa em Geografia (Anpege).

D D p.138-161, V.15, n.26, jan./mar. 2019. 
horizontes superficiais por erosão laminar. Nos fundos de vale marcados por terrenos aluviais, a intercalação de neossolos flúvicos e gleissolos também é passível de verificação em campo. Fatores locais, como a declividade das vertentes e a proximidade do nível freático, respondem pela diversidade pedológica.

Tais solos foram desenvolvidos sob características climáticas que apresentam duas estações bem definidas, conforme afirma Torres (2006, p. 162): “[...] uma que vai de outubro a abril, com temperaturas mais elevadas e maiores precipitações pluviométricas, e outra de maio a setembro, mais fria e com menor presença de chuvas". Em relação ao uso da terra, este esteve influenciado pela atividade de plantio do café, que promoveu a remoção de conjuntos florestais para a implantação desta prática voltada para a economia externa. Atualmente, predominam gramíneas (principalmente exóticas) associadas à atividade pastoril.

Em linhas gerais, o quadro geomorfológico do município de Juiz de Fora pode ser inserido nos domínios do Planalto Atlântico, situado na Serra da Mantiqueira setentrional, na unidade de serranias da zona da mata mineira, de acordo com a taxonomia estabelecida pelo Radambrasil (1983). As serranias da zona da mata mineira são assinaladas por Gatto et. al (1983) como feições de formas alongadas, com destaque para as cristas simétricas alinhadas, escarpas de falha e sulcos estruturais, cujos substratos rochosos são de granulitos, charnoquitos e migmatitos.

De acordo com a Companhia Mineradora de Minas Gerais (COMIG, 2002), o embasamento geológico se estrutura pelo Complexo Mantiqueira, megassequência Andrelândia e pela ocorrência de formações quaternárias associadas aos depósitos sedimentares nos fundos de vales sedimentados em consonância às planícies e terraços fluviais, controlados por linhas de falha indiscriminadas de orientação NW-SE.

O Complexo Mantiqueira está situado na porção média da bacia hidrográfica do Ribeirão dos Burros, e a litologia correspondente varia de hornblenda-biotita ortognaisse tonalítico a granítico, rocha anfibolítica, enquanto a megassequência Andrelândia se encontra no setor norte e numa faixa ao sul da BHRB, rica em biotita gnaisse bandado, com intercalações de quartzito impuro (q), gnaisse quartzoso, rocha anfibolítica (a) e, subordinadamente, granada gnaisse e rocha calcissilicática (COMIG, 2002) (Figura 1). 
Figura 1: Mapa de localização da bacia hidrográfica ribeirão dos Burros, com apresentação das unidades litológicas e falha reconhecida.
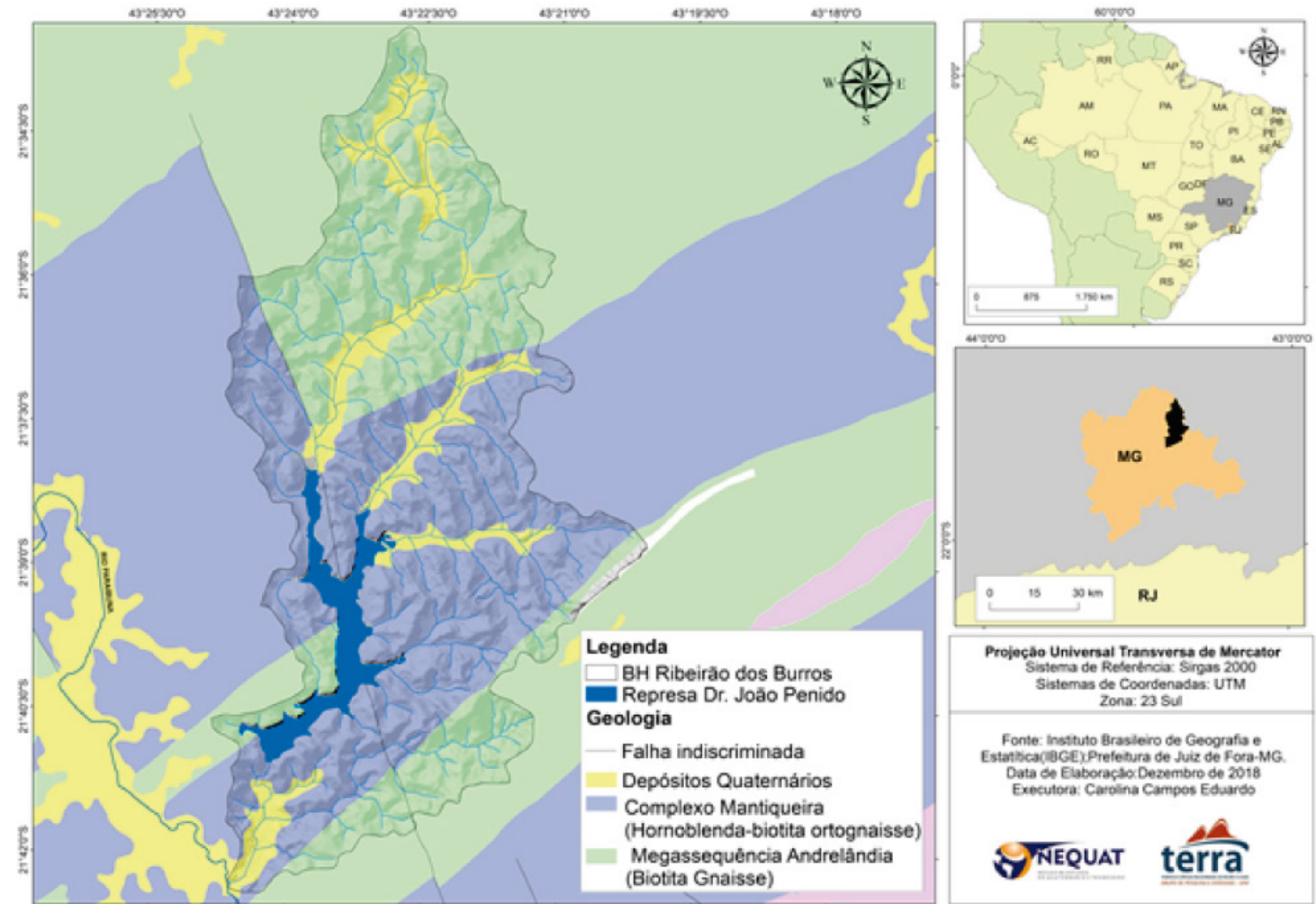

Em meio aos morros mamelonares de Juiz de Fora, Ab’Sáber (2010, p. 181) destaca que, neste município, a feição de planície fluvial favoreceu a expansão urbana, por meio do assentamento na porção central, como "[...] compartimentos de relevo situados a montante de soleiras rochosas, sob a forma de planícies e baixos terraços de extensão excepcionalmente ampliada”.

Sobre o relevo desse município, Eduardo o descreve como feições geomórficas

[...] majoritariamente elevadas, estabelecendo setores de encostas do relevo como áreas suscetíveis a escorregamentos. A apreciação clinográfica confere aos processos de ocupação urbana uma pauta relevante no âmbito do planejamento, uma vez que a energia gravitacional do relevo se associa a essa informação. $\mathrm{O}$ quadro altimétrico de Juiz de Fora está expresso pela diferenciação entre áreas de domínios planos e feições suavizadas daquelas de domínios de morros e morrotes (EDUARDO, 2018, p. 81).

Ressalta-se ainda que, na BHRB, está abrigado o principal manancial de Juiz de Fora, a represa Doutor João Penido (Figura 2), que contribui para, aproximadamente, 50\% do abastecimento desta cidade. Esse reservatório, construído em 1934, possui capacidade volumétrica de 16 bilhões de litros d’água e é responsável pelo abastecimento de duas estações de tratamento de água.

D

D Revista da Associação Nacional de Pós-graduação e Pesquisa em Geografia (Anpege). 
Figura 2: Lago de formação da represa Dr. João Penido.

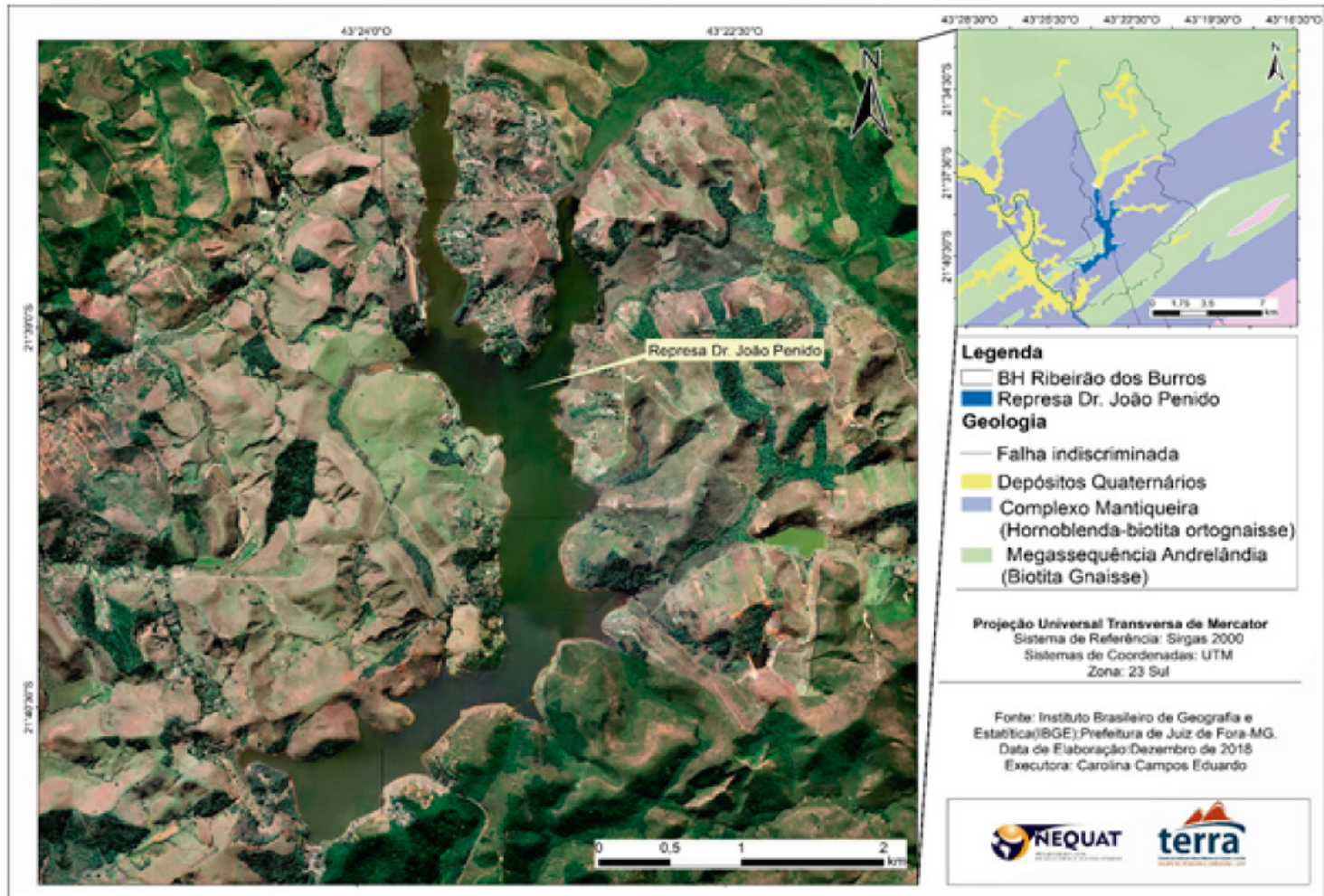

A ocupação das margens desse manancial é regida pela Lei Municipal n 6.087/1981, dispondo sobre o parcelamento, o uso e a ocupação das terras nesta área. Já a Lei Municipal no 7.255/1987 determina a preservação dessa represa, proibindo, por meio do Artigo $1^{\circ}$, as atividades de pesca, o uso de barcos, de canoas e lanchas e a natação. Além destes critérios, ficariam vetadas as novas construções e estabelecida a determinação para os proprietários das edificações existentes reverem as formas de lançamento de esgotos nesse manancial. Entretanto, a legislação municipal não foi suficiente para inibir a expansão e o parcelamento do solo em loteamentos, nessa porção da área de estudo.

No intuito de rever essa situação, a Prefeitura de Juiz de Fora, em 2012, criou um grupo de trabalho para desenvolver estudos para a preservação da bacia da represa Dr. João Penido, formado por membros da administração municipal, cujos objetivos são: a) a análise dos instrumentos de controle de parcelamento, uso e ocupação da bacia da represa; b) a análise da constituição de uma área de amortecimento desta bacia; e c) a proposta para o desenvolvimento sustentável desta bacia e de seu entorno.

Posteriormente, por meio da Lei Complementar n. 023/2015, foram estabelecidas as "zonas especiais no entorno da bacia de contribuição para o lago da represa Dr. João Penido". Estas áreas reservadas foram nomeadas de ZE1 e ZE2, com diferentes tipos de atividades permitidas visando à preservação do manancial em questão. Embora a criação dessas porções diferenciadas tenha 
sido relevante para a regularização das atividades na represa Dr. João Penido, ainda é necessário o avanço sobre as questões dos seus recursos hídricos, uma vez que não foi criada nenhuma unidade de preservação para o lago.

\section{Resultados e discussões}

Por meio do zoom para o recorte do mapa de feições geomorfológicas (Figura 3), tem-se: em A, a feição de planície fluvial (Apf), onde está representada, na orientação NE-SW, a retificação do córrego Grama; em B, no recorte da imagem em 1983, já é possível inferir, por meio do fracionamento do terreno, o estágio de perturbação do sistema natural, pela captação de água no uso das atividades agrícolas locais; e, em C, no recorte em 2007, não ocorreram mudanças relevantes, indicando a consolidação do estágio pós-perturbação.

Contudo, pela imagem do Google Earth, datada de 2018, é possível identificar uma nova mudança no sistema já alterado, com a expansão da rodovia que interliga a MG267 com a BR040. Utilizando-se da classificação genética proposta por Peloggia et al. (2014) para tipos de terrenos, solos e depósitos tecnogênicos, esta área pode entendida como "terreno tecnogênico de agradação", em depósitos sedimentares relacionados às redes de drenagem atuais.

Figura 3: Trecho da bacia correspondente à retificação do córrego Grama. A) em amarelo: planície fluvial antropogênica (Apf) com feições de morros nas áreas adjacentes; B) recorte da imagem aérea de 1983; C) recorte da imagem aérea de 2007; D) imagem aérea do Google Earth, em 2018.
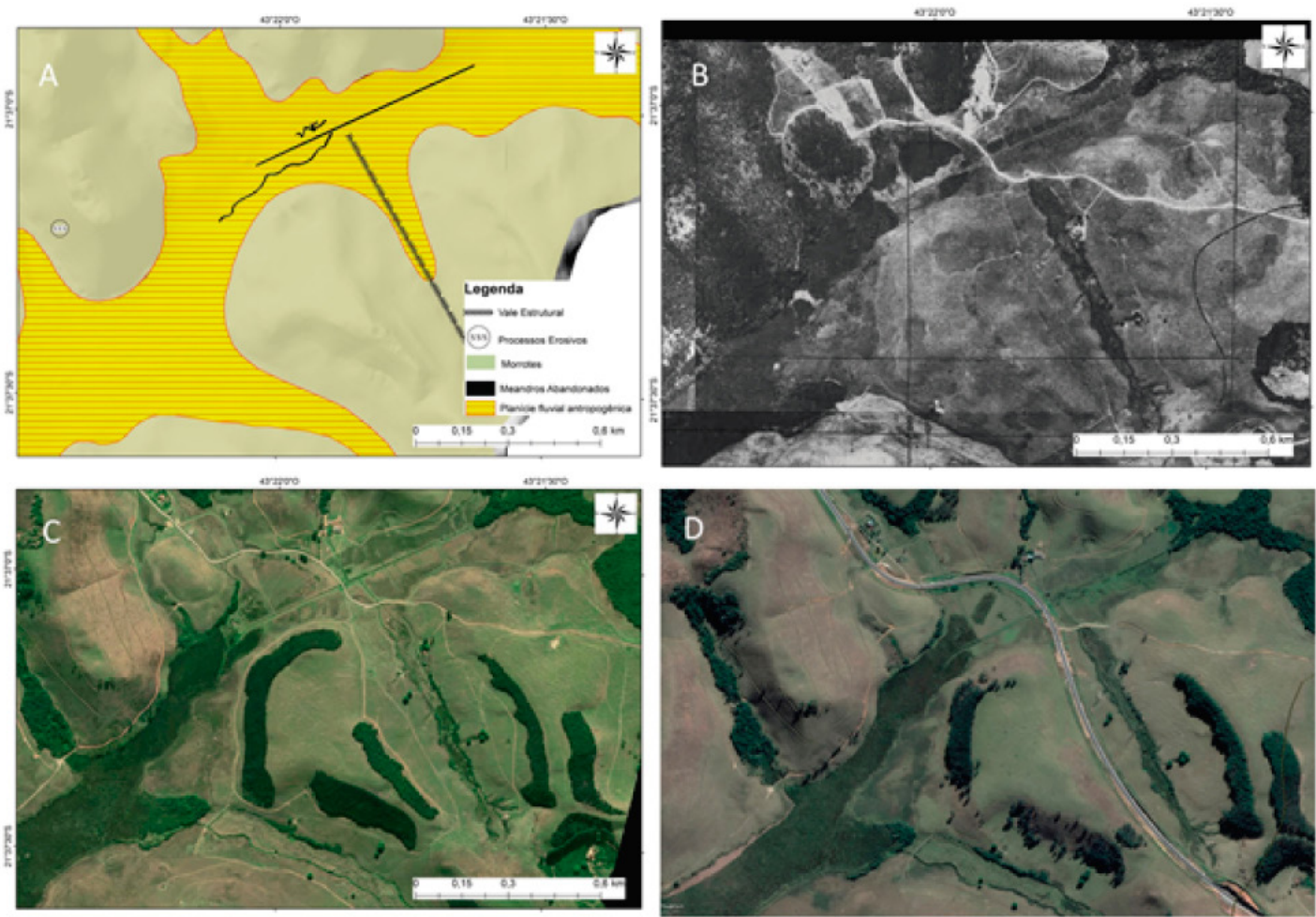

Fonte: Google Earth Pro, 2018. 
Essa nova rodovia foi implantada para atender às demandas do transporte do trecho da rodovia MG353 com acesso rodoviário ao Aeroporto Regional da Zona da Mata, localizado em Goianá. Bucci (2015) aponta sobre a construção de um trecho da rodovia na região de recarga hídrica da represa Dr. João Penido e ressalta preocupação com os impactos negativos advindos com a execução desta obra, mesmo com as medidas de compensação propostas no processo de licenciamento ambiental do empreendimento. A Figura 4 mostra uma parcela da via de acesso implantada.

\section{Figura 4: A) Vista frontal da planície fluvial lacustre no córrego Grama, com vegetação de gramíneas e, ao fundo, o lago do manancial; B) vista lateral da rodovia de interligação, impermeabilizando parte da planície observada em A. Fotografia de Carolina C. Eduardo (fevereiro/2019).}
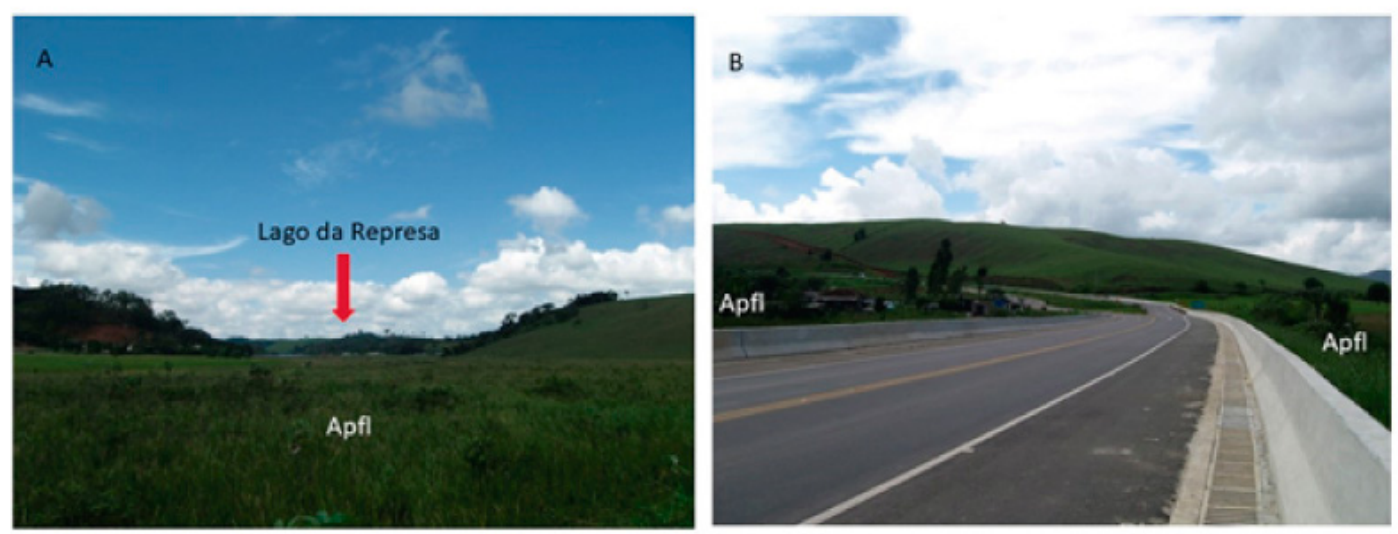

Ao chamar a atenção para a importância das espécies de plantas aquáticas como depuradoras e purificadoras da água, Bucci (2015, p.113) alega o quanto "a construção dessa rodovia pode afetar esse processo natural de purificação [...] e ainda contribuir para o assoreamento e sedimentação dos corpos d'água devido à movimentação de terra realizada no local". Essa autora mostra ainda, na etapa de construção da estrada (isto é, durante a fase de perturbação), o tratamento inadequado dado aos resíduos da construção, dispostos nas margens dos cursos d' água, segundo se observa na Figura 5. 
Figura 5: Resíduos das obras da rodovia nas margens do Ribeirão dos Burros, em fevereiro de 2015.

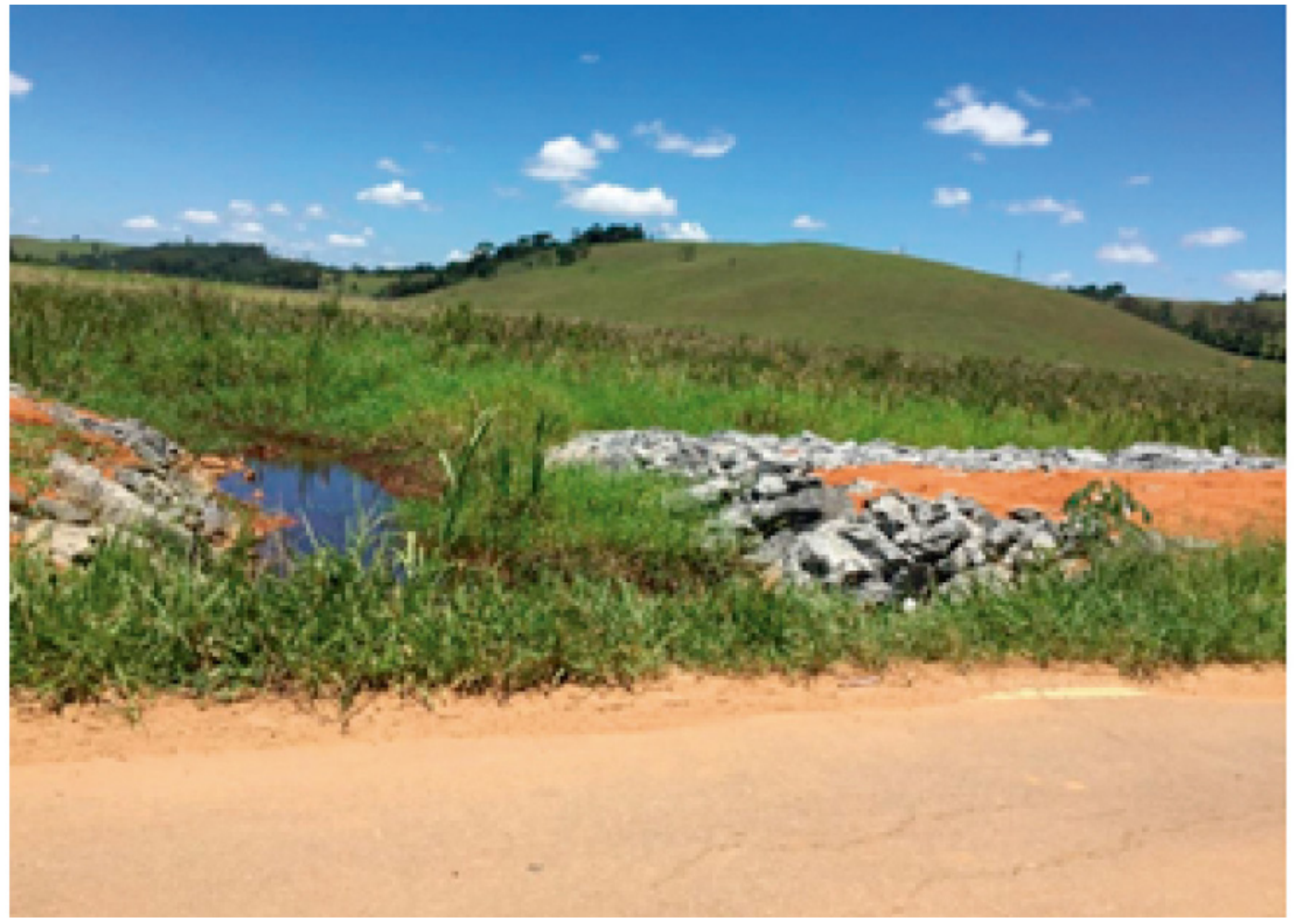

Fonte: Bucci, 2015.

Na Figura 6, as ocupações são incrementadas no entorno do lago da represa Dr. João Penido, com a consolidação e a expansão de loteamentos. Segundo Pellogia et al. (2014), esses terrenos podem ser classificados como tecnogênicos de degradação, considerados naturais e alterados pela perda volumétrica de material, e geneticamente atribuídos de cicatrizes tecnogênicas construídas, cujas formas de transformação ocorreram pela técnica de cortes de terraplanagem e aterramentos.

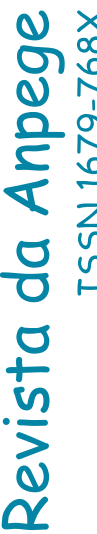

D

D Revista da Associação Nacional de Pós-graduação e Pesquisa em Geografia (Anpege).

$D^{D}$ p.138-161, V.15, n.26, jan./mar. 2019. 
Figura 6: Ocupação na área próxima ao manancial Dr. João Penido. A) Áreas destinadas aos loteamentos, em 1983 e 2007, próximas ao manancial; B) recorte da imagem aérea de 1983; C) recorte da imagem de 2007; D) imagem aérea do Google Earth, em 2018.
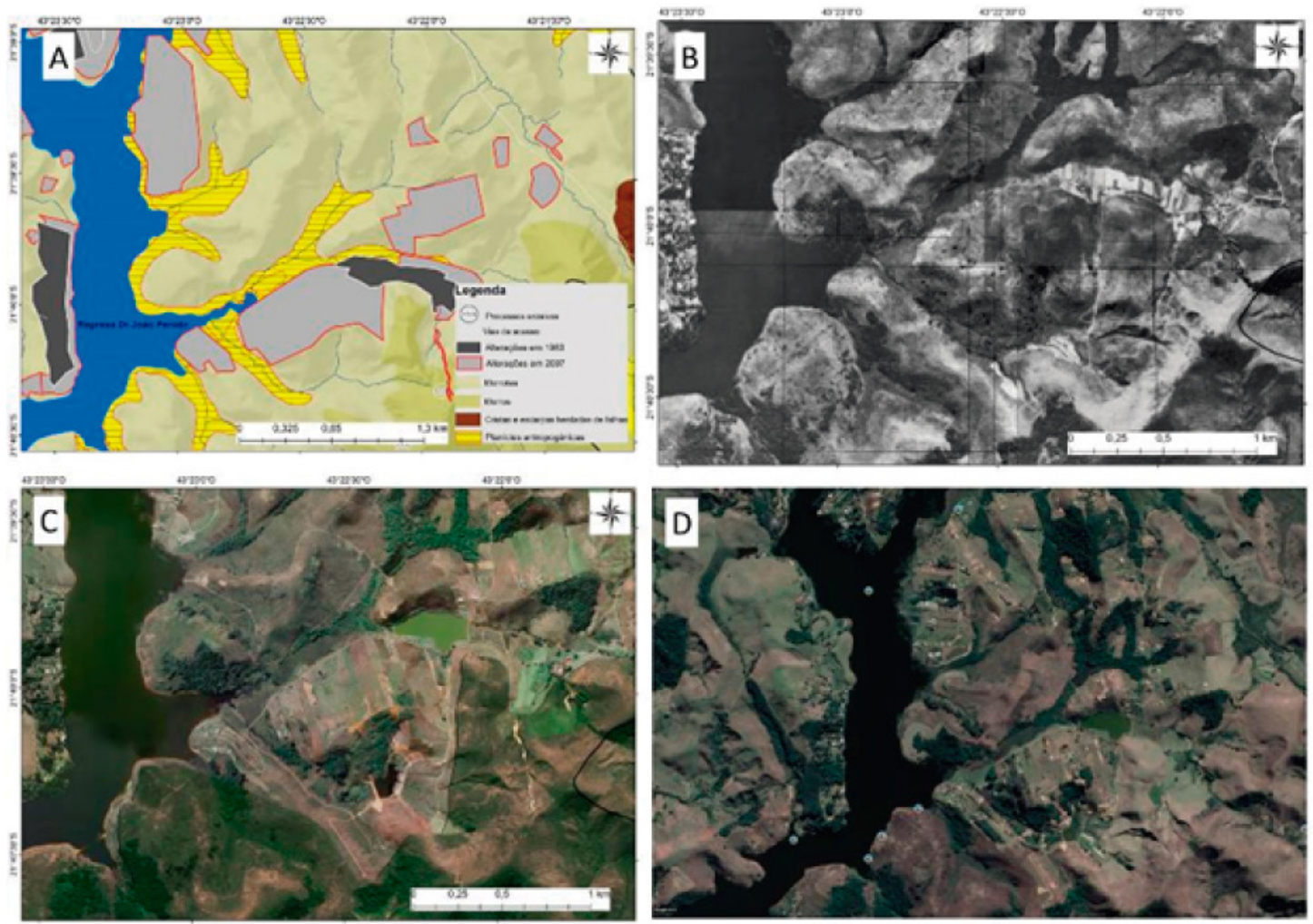

Fonte: Google Earth Pro, 2018.

Outro agrupamento de feições morfológicas naturais, na BHRB, revela a presença de trechos de canais meândricos abandonados, identificados próximos à foz do Ribeirão dos Burros (Figura 7A), confirmados pela imagem atual do Google Earth, enquanto, na Figura 8, se revelam alguns aspectos deste setor, por meio do trabalho de campo. Nessa porção da área de estudo, atrelados à presença de meandros abandonados, podem ser visualizados distintos níveis de terraços, indicando o retrabalhamento de canais fluviais ao longo do período Quaternário, em uma escala temporal superior à observada no presente trabalho. 
Figura 7: Meandros abandonados próximos à foz da bacia hidrográfica ribeirão dos Burros. A) Feições de relevo próximas ao Ribeirão dos Burros; B) recorte parcial da área, em 1983; C) recorte parcial do entorno da área, em 2007; D) imagem do Google Earth, destacando os meandros abandonados.
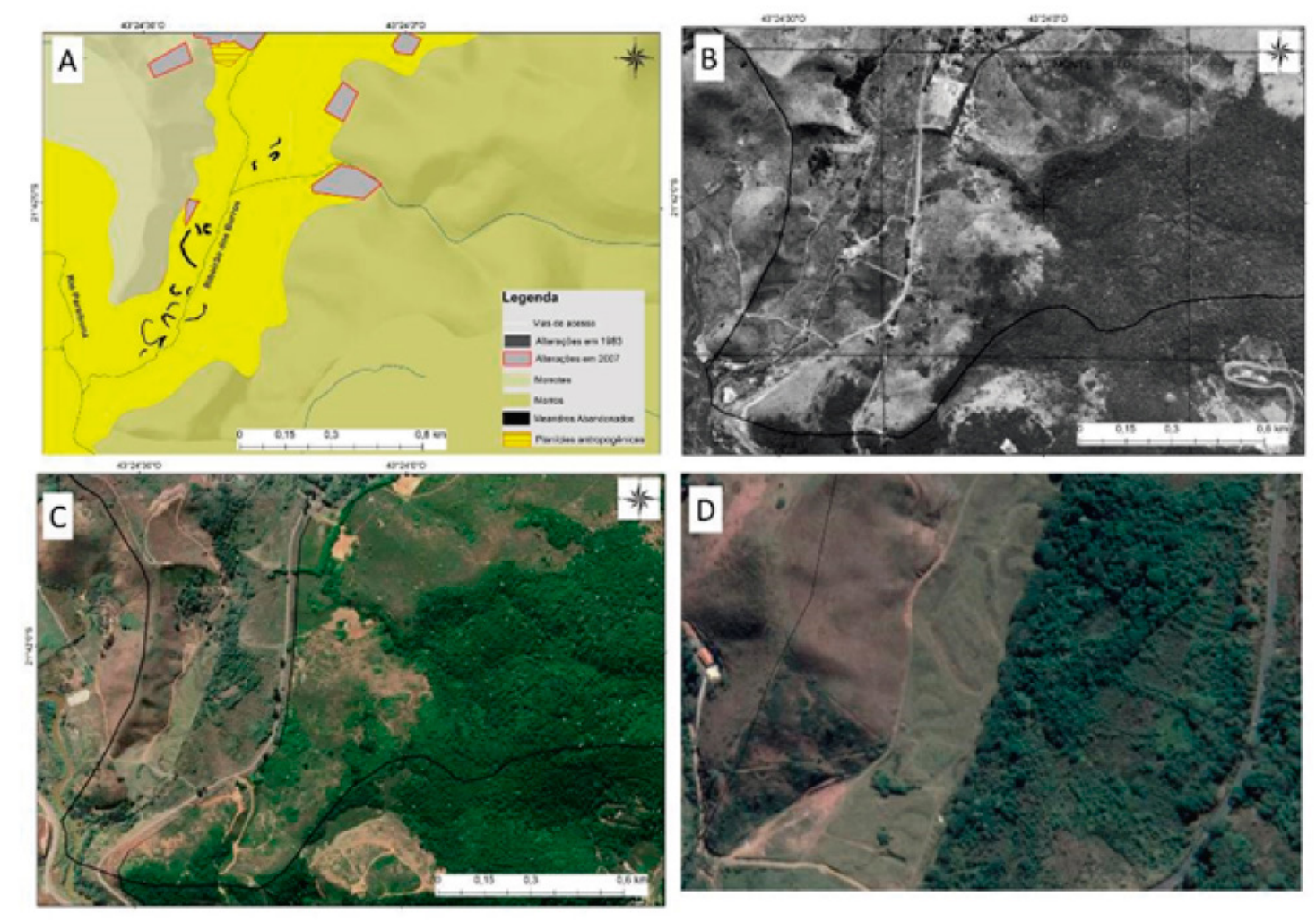

Fonte: Google Earth Pro, 2018.

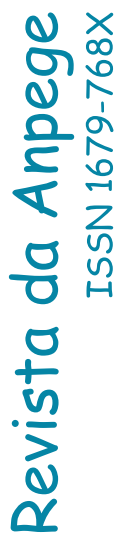

D D Devista da Associação Nacional de Pós-graduação e Pesquisa em Geografia (Anpege).
p.138-161, V.15, n.26, jan./mar. 2019.

D $D$ 
Figura 8: A) Planície fluvial sobre meandros abandonados ladeados por morrotes (Dmr), com vegetação de gramíneas, com corte antropogênico na sua vertente; B) destaque para o corpo hídrico na Apft, cujos meandros abandonados se encontram preenchidos por sedimentos e cobertos por gramíneas; C) Ribeirão dos Burros (conhecido localmente como rego da Lili), com processo de deposição lateral de areias. Fotografia de Carolina C. Eduardo (fev./2019).

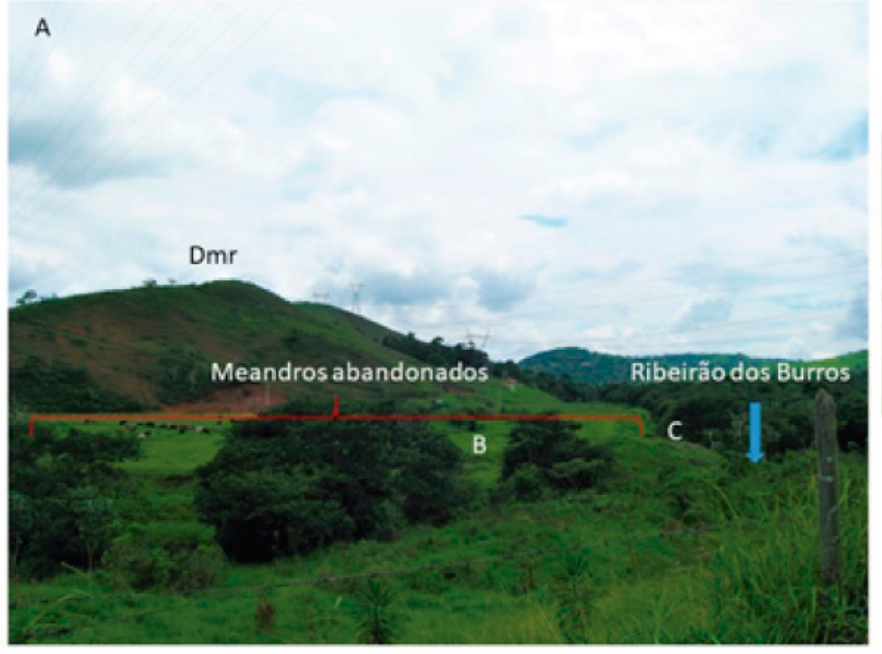

A)-Meandros abandonados na Apft (planície fluvial associada a terraços), com uso destinado a pecuária. Dmr: Relevo em Dissecação Homogênea em morrotes. B). Imagem parcial de um pequeno corpo hídrico formado na Apft. C)- Deposiçăo de sedimentos arenosos provenientes do transporte erosivo.
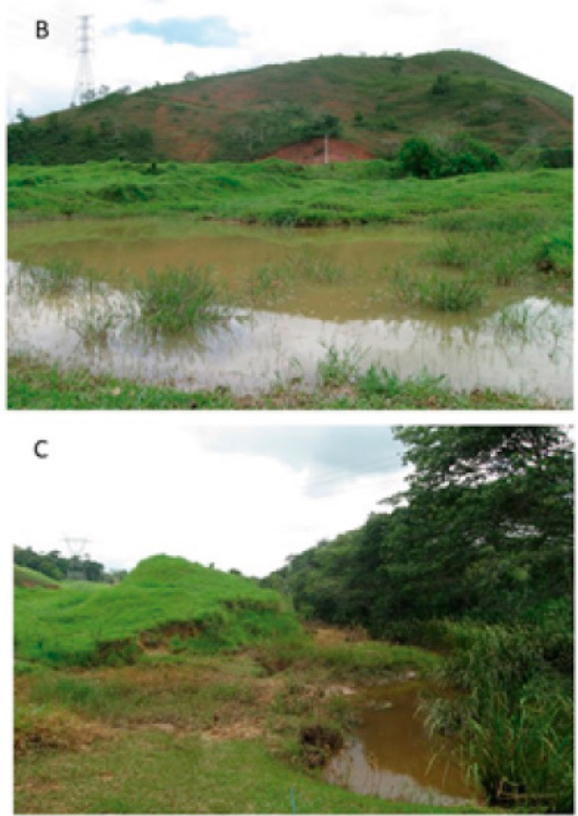

Foi observado também que a bacia hidrográfica ribeirão dos Burros possui áreas destinadas ao uso agrícola, caracterizadas como terrenos tecnogênicos modificados geneticamente em horizontes alterados pela ação mecânica de ferramentas utilizadas para o cultivo, originando, possivelmente, solos compactados com a presença de pesticidas.

Em relação ao manancial Dr. João Penido, Bucci e Oliveira (2012) realizaram campanhas mensais, durante o período de julho de 2009 a junho de 2010, em diferentes pontos de amostragem, e apresentaram dados sobre a qualidade da água no reservatório. Esses autores realizaram análises químicas com parâmetros de oxigênio dissolvido (OB), potencial hidrogenionico (pH), demanda bioquímica de oxigênio (DBO), turbidez e fósforo total (PT), cujos resultados destoaram dos parâmetros estabelecidos pela resolução 357, de 2005 (que trata "sobre a classificação dos corpos de água e diretrizes ambientais para o seu enquadramento, bem como estabelece as condições e padrões de lançamento de efluentes, e dá outras providências"). Na imagem apresentada pela Figura 9, estão elencados os pontos de coletas de amostras para a efetivação das análises. 
Figura 9: Pontos de coleta de amostras para a realização de análises químicas, apresentados por Bucci e Oliveira (2012).

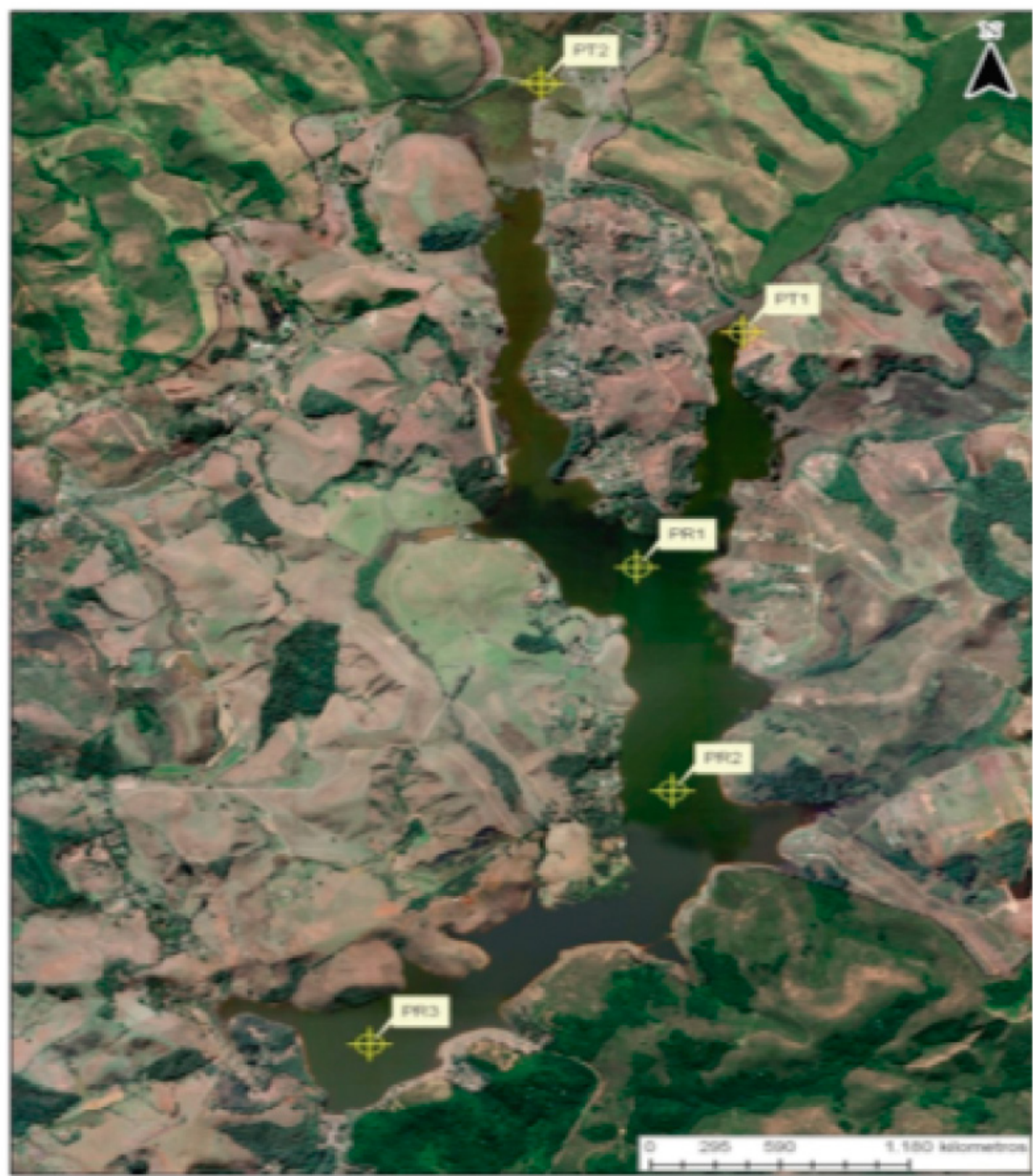

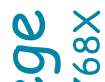

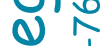

을ำ

ह

Fonte: Bucci e Oliveira (2012).

Por meio de suas análises, Bucci e Oliveira (2012, p. 21) afirmam que "os resultados mostraram que o manancial vem sofrendo deterioração da qualidade das águas, provocada pelas ações antrópicas realizadas na região da bacia da represa, principalmente em suas margens".

Fonte: Buccie Oliveira (2012). 
No bairro Parque Independência, localizado no divisor de águas da BHRB, próximo à nascente de um dos afluentes do córrego Remonta, tem-se uma feição erosiva considerada de grande porte, associada diretamente às alterações locais ligadas à implantação do loteamento adjacente, como se pode ver nas imagens da Figura 10.

Figura 10: A) Imagem aérea de 1983 (o círculo em cor amarela destaca a feição erosiva); B) imagem aérea de 2007 (em destaque, a feição erosiva); C) visão panorâmica do foco erosivo. Fotografia de Carolina C. Eduardo (fevereiro/2019).
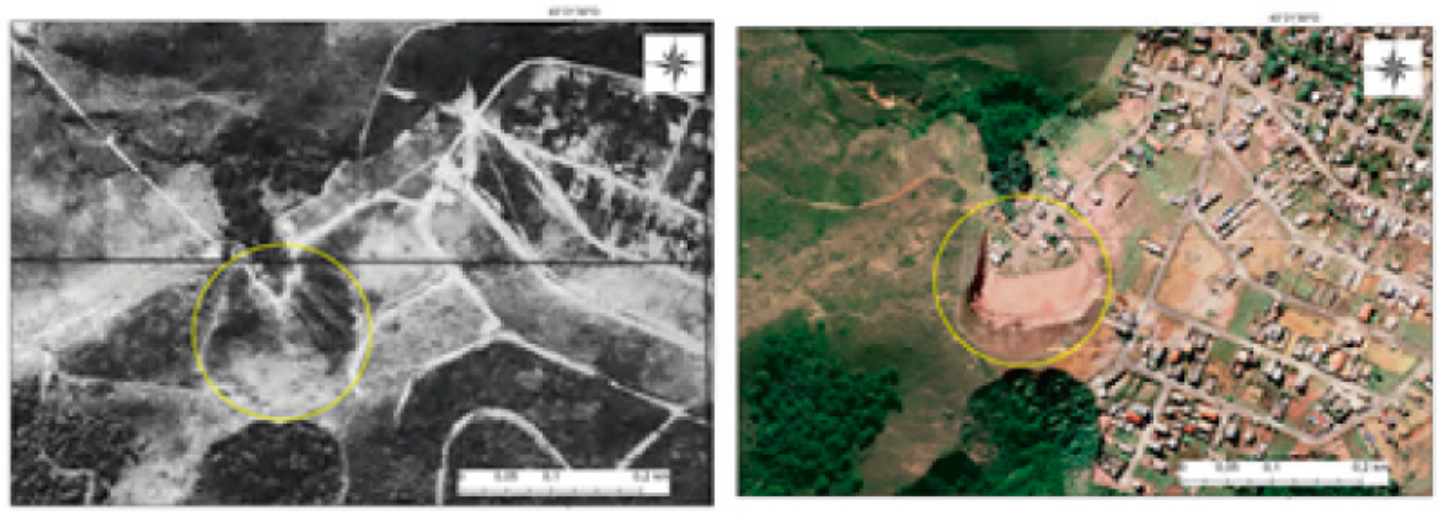

Na Figura 11, são apresentados os principais loteamentos em expansão, na bacia hidrográfica do Ribeirão dos Burros. Observou-se que a maioria dos loteamentos foi implantada na planície fluvial ou em suas proximidades, pelo fato de possuírem declividades suaves, e, além disso, a ocupação no entorno do lago da represa Dr. João Penido está associada ao seu valor estético, financeiro e de especulação imobiliária. Foram identificados também processos erosivos sem diferenciação da fase em que se encontra, seja laminar, ravinamento ou voçorocas. 
Figura 11: Mapa de feições geomorfológicas, com demarcação dos principais loteamentos em expansão identificados para os anos de 1983 e 2007. Fonte: Elaborado pelos autores a partir da Base Cartográfica do Município de Juiz de Fora.

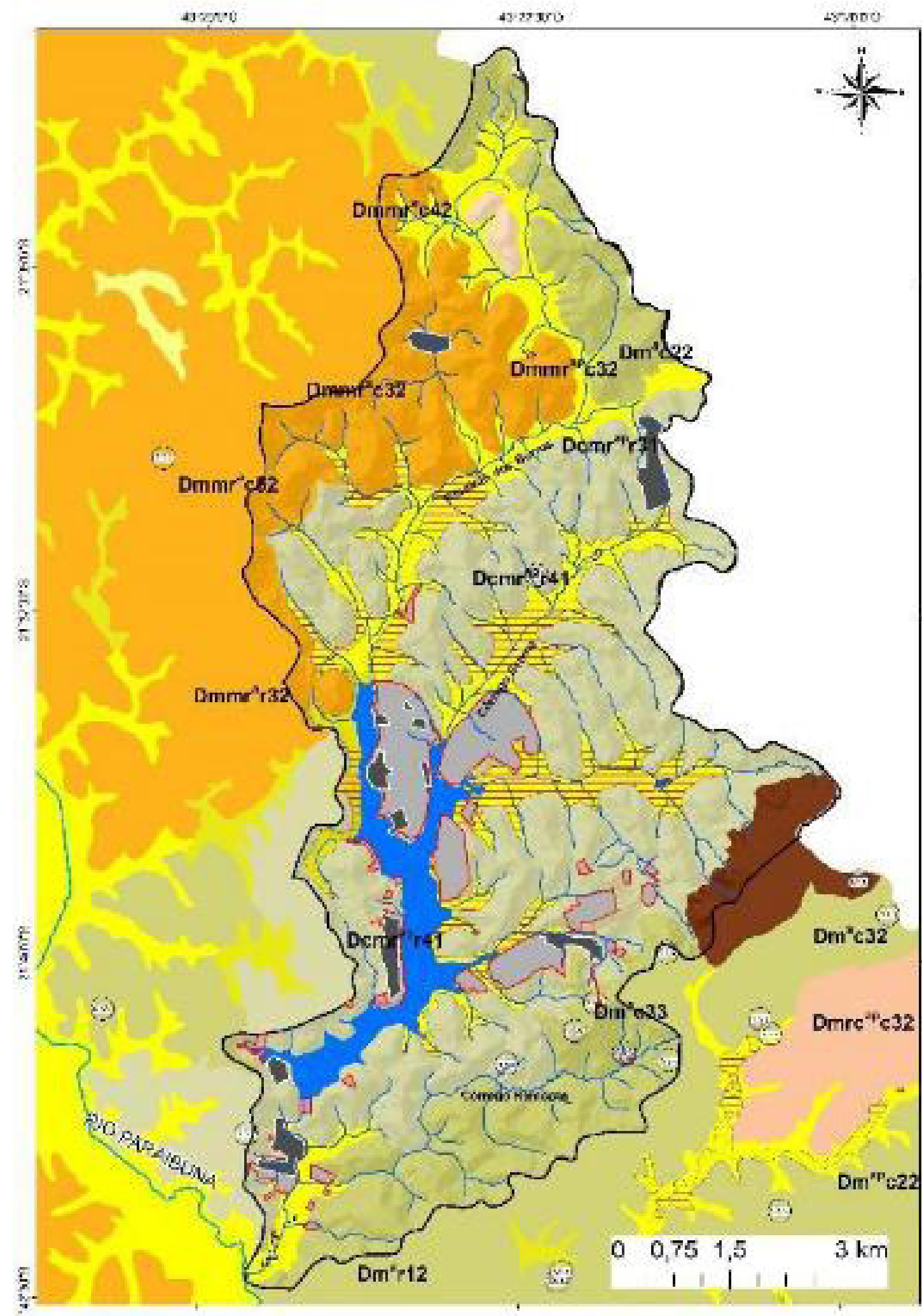

$\frac{0}{8}$

\section{SISTEMAS DE RELEVO ORIGINAIS}

Modelados de Agradaçáo (A):

Apfl- Planicie flúvio-lacustre: planicies associadas ao represamento das águas fluviais.

Modelados de Dissecaçăo Homogênea (D):

Dcmr -Colinas e Morrotes: Predominio de colinas e esporadicamente morrotes, com topos convexos com média profundidade de dissecaç̧o e espessas coberturas superficiais argilosas.

Dm-Morros: Morfologias mamelonares quaternárias de topos convexos a aplainados e vertentes convexo retilineas com coberturas superficiais argilosas. a) topos aguçados;ap) topos aplainados; c) topos convexos.

Dmmr - Morros e morrotes: Predominio de morros com morrotes esporádicos, constituindo grande parte do grabén do Parabuna com topos convexos e vertentes convexas e resl ineas; espessas coberturas superficiais argilosas. Dmr Morrotes: Morfologias mamelonares quaternárias rebaixadas de topos convexos e vertentes convexo retilineas com coberturas superficiais argilosas.

\section{Modelados de Dissecacao em Controle Estrutural (DE):}

DEse- Cristas e escarpas herdadas de falhas: Dominio marcado por flancos escarpados ingremes com coberturas superficiais pouco evoluidas e expressivo entalhe da drenagem com topos aguçados e vertentes retilineas.

$\begin{array}{ll}\text { Relevo Simbolizado } & \text { Categorias de Uso } \\ \text { SSS Processos erosivos } & \text { Alteraçōes em } 1983\end{array}$

Sis Pianicies urbanizadas $\quad \square$ Alteraçes em 2007

Represa Dr. Joåo Penido

Bacia Hidrográfica Ribeiråo dos Burros

D 


\section{Considerações finais}

As análises geomorfológicas conduzidas pela categorização da paisagem em sua morfologia original e, por conseguinte, as transformações antropogênicas foram capazes de fornecer conhecimento, mesmo que preliminar, da evolução morfológica local. Essas análises são instrumentos relevantes para a gestão pública e no discernimento técnico e operacional de políticas voltadas para o planejamento ambiental e territorial. Diante disso, tornam-se cada vez mais necessárias as práticas de preservação do acervo bibliográfico, composto de plantas cadastrais, imagens aéreas, fotografias e mesmo de depoimentos da comunidade local, e a sua sincronia com os SIGs, como ferramentas de organização, de edição e de leitura de mapas retrospectivos.

Na bacia hidrográfica do Ribeirão dos Burros, ficam expostas as modificações antrópicas, em especial, no entorno do lago da represa Dr. João Penido. Os processos antrópicos de cortes e terraceamentos evidenciam uma nova dinâmica no sistema geomorfológico local, que responderá, em magnitude e frequência, nas suas taxas de sedimentação e de erosão. Nesse sentido, a continuidade dos estudos para essa área é necessária para a qualificação e a quantificação dessas taxas.

Ademais, sobre a represa Dr. João Penido, foi possível diagnosticar a insuficiência no sistema legislativo ambiental quanto à tomada de medidas decisórias em relação à conservação e à fiscalização no entorno do manancial e dos recursos hídricos que compõem a bacia hidrográfica como um todo. As atividades agrícolas desenvolvidas nas planícies fluviais resultaram em alterações significativas nas formas fluviais, pois cursos d'águas foram retificados e, consequentemente, leitos foram aterrados ou abandonados. Estas formas de relevo confluem para uma investigação mais detalhada quanto à formação de terraços, além da própria dinâmica hidrogeomorfológica, que se manifesta comumente em outras bacias hidrográficas dos sistemas tropicais brasileiros.

Ressalta-se ainda que, para a proposta de estudo de cartografia evolutiva ou retrospectiva apresentada neste artigo, amparada na identificação de estágios de uma morfologia original e antropogênica, existiu um enfrentamento técnico para o manuseio dos insumos cartográficos no que tange à utilização das imagens aéreas antigas. Estas imagens apresentaram algumas distorções, uma vez que houve a necessidade de se escanear cenas que apresentaram dificuldades no processo de georreferenciamento.

Em conclusão, o presente trabalho se afasta da ideia de encerrar as discussões sobre a geomorfologia antropogênica. Ao contrário disto, tem a proposição de contribuir com os estudos voltados para o mapeamento de feições de relevo em detalhe apoiado na cartografia evolutiva ou retrospectiva, buscando trazer o debate bibliográfico e a aplicação de metodologias e técnicas que se empenham no tratamento da capacidade de expressar graficamente os elementos antropogênicos 
na paisagem, e, assim, substanciar a sistematização desses dados com o aporte das ferramentas de geoprocessamento e de geotecnologias disponíveis ao pesquisador.

\section{Agradecimentos}

À Coordenação de Aperfeiçoamento de Pessoal de Nível Superior (CAPES), pela bolsa integral concedida a Carolina Campos Eduardo, em seu curso de doutorado em andamento.

\section{Referências bibliográficas}

1. AB'SÁBER, A. N. O sítio urbano de São Paulo. In: MODENESI-GAUTTIERI, M. C. et al. (org.). A obra de Aziz Nacib Ab’Sáber. São Paulo: Beca-BALL, p. 180-214, 2010.

2. BUCCI, M. M. H. S.; OLIVEIRA, L. F. C. de. A interferência das atividades antrópicas na qualidade da água em reservatório de abastecimento urbano. Estudo de caso: represa Dr. João Penido (Juiz de Fora, MG). In: Eclética Química Journal, v. 37, n. 1, p. 09-22, 2012.

3. Estudo da qualidade da água na represa Dr. João Penido: metais, agrotóxicos, índices de qualidade da água e de estado trófico. Tese (Doutorado). Programa de PósGraduação em Ecologia. Instituto de Ciências Biológicas, Universidade Federal de Juiz de Fora. Juiz de Fora/MG, 2015, 163 p.

4. BROWN, E. H. O homem modela a Terra. In: Boletim Geográfico, v. 30, n. 222, p. 1-18, 1971.

5. BROWN, A.; TOOTH, S.; BULLARD, J. E.; THOMAS, D. S. G.; CHIVERRELL, R. C.; PLATER, A. J.; MURTON, J.; THORNDYCRAFT, V. R.; TAROLLI, P.; ROSE, J.; WAINWRIGHT, J.; DOWS, P.; AALTO, R. The geomorphology of the Anthropocene: emergence, status and implications. In: Earth Surface Processes and Landforms, v. 42, n. 1, p. 71-90, 2017. Disponível em: https://onlinelibrary.wiley.com/doi/full/10.1002/ esp.3943. Acesso em: 26 abr. 2019.

6. CORDOVIL, W. D. Do caminho novo a Manchester Mineira: as dinâmicas socioespaciais da gênese e evolução do município de Juiz de Fora no contexto regional da Zona da Mata Mineira. Dissertação (Mestrado em Geografia). Programa de Pós-Graduação em Geografia. Instituto de Ciências Humanas - Universidade Federal de Juiz de Fora, 2013, 245 p.

7. COMPANHIA DE SANEAMENTO MUNICIPAL (CESAMA). Juiz de Fora. Mananciais. Represa Dr. João Penido. Disponível em:<www.cesama.com.br>. Acesso em: 22 dez. 2018.

8. CHEMEKOV, Y. F. Technogenic deposits. In: Inqua Congress, 1983, p. 62.

D 
9. CRUTZEN, P. J.; STOERMER, E. F. The “Anthropocene”. In: IGBP News Letter, n. 41, p. $17-18,2000$.

10. DÁVID, L.; LONTAI-SZILÁGYI, Z.; BAROS, Z. The impact of tourism and sports activities. In: SZABÓ, J.; LÓRANT, D.; LÓCZY, D. Anthropogenic geomorphology: a guide to man made landforms. London: Springer, 2010.

11. DOUGLAS, I. The urban environnment. London: Edward Arnold, 1983, 229p.

12. EDUARDO, C. C. Cartografia geomorfológica comparada: aplicações no município de Juiz de Fora (MG) como subsídio ao planejamento. Dissertação (Mestrado em Geografia). Programa de Pós-Graduação em Geografia. Instituto de Ciências Humanas - Universidade Federal de Juiz de Fora, 2018, 158p.

13. FELIPPE, M. F.; JUNIOR, A. P. M.; PESCIOTTI, H., COELI, L. Nascentes antropogênicas: processos tecnogênicos e hidrogeomorfológicos. In: Revista Brasileira de Geomorfologia, v. 14, n. 4 , p. 279-286, 2014.

14. FUNDAÇÃO ESTADUAL DE MEIO AMBIENTE (FEAM). Mapas de solos do estado de Minas Gerais. Banco de Solos de Minas Gerais, 2010.

15. GARCIA, R. A.; NOGUEIRA, M. A inserção das cidades médias mineiras na rede urbana de Minas Gerais. Universidade Federal de Minas Gerais. In: Seminário da CEDEPLAR Centro de Desenvolvimento e Planejamento Regional da UFMG. Seminários [...]. Minas Gerais: UFMG. Disponível em: http://www.cedeplar.ufmg.br/seminarios/seminario_ diamantina/2008/D08A100.pdf. Acesso em 26 abr.2019.

16. GATTO, L. C. S.; RAMOS, V. L. S.; NUNES, B. T. A.; MAMEDE, L.; GÓES, M. H. B.; MAURO, C. A.; ALVARENGA, S. M.; FRANCO, E. M. S.; QUIRICO, A. F.; NEVES, L. B. Geomorfologia. In: BRASIL. Ministério de Minas e Energia. Projeto Radambrasil. Rio de Janeiro: Ministério de Minas e Energia, 1983, v. 32, p. 305-384 (Série Levantamento de Recursos Naturais).

17. GERASIMOV, I. P. Anthropogene and its major problem. In: Boreas, v. 8, n. 1, p. 23$30,1979$.

18. KERÉNYI, A. Human impact in a systems approach. In: SZABÓ, J.; LÓRANT, D.; LÓCZY, D. Anthropogenic geomorphology: a guide to man made landforms. London: Springer, 2010.

19. KOHLER, H. C. A escala na análise geomorfológica. In: Revista Brasileira de Geomorfologia, v. 3, n. 1, p. 21-33, 2002. 
20. INSTITUTO BRASILEIRO DE GEOGRAFIA E ESTATÍSTICA (IBGE). Coordenação de Recursos Naturais e Estudos Ambientais. Manual técnico da vegetação brasileira. Rio de Janeiro: IBGE, 1992 (Série Manuais Técnicos em Geociências).

21. JUIZ DE FORA. Lei nº 6087, de 4 de dezembro de 1981. Dispõe sobre o parcelamento, uso e ocupação do solo, na área da bacia hidrográfica da represa Dr. João Penido, em Juiz de Fora, e dispõe outras providências. Disponível em: https://jflegis.pjf.mg.gov. br/c_norma.php? chave $=0000017564$. Acesso em: 21 dez. 2018.

22. Lei n 7.255, de 15 de dezembro de 1987. Proíbe a utilização da represa Dr. João Penido para fins incompatíveis com sua destinação. Disponível em: https://c-maramunicipal-da-juiz-de-fora.jusbrasil.com.br/legislacao/338773/lei-7255-87. Acesso em: 21 dez. 2018.

23. Lei Complementar $\mathbf{n}^{\mathbf{0}} \mathbf{0 2 3}$, de 22 de junho de 2015. Cria zonas especiais no entorno da bacia de contribuição para o lago da represa Dr. João Penido. Disponível em: https://www.pjf.mg.gov.br/e_atos/anexos/023\%20a_150628.doc. Acesso em: 21 dez. 2018.

24. LUZ, R. A. Mudanças geomorfológicas na planície fluvial do rio Pinheiros, São Paulo (SP), ao longo do processo de urbanização. Tese (Doutorado em Geografia). Faculdade de Filosofia, Letras e Ciências Humanas - Universidade de São Paulo, São Paulo/SP, 2015,245 p.

25. MINAS GERAIS. Fundação Estadual do Meio Ambiente. Banco de solos de Minas Gerais: mapas de solo do Estado de Minas Gerais. Belo Horizonte: Feam, 2010. Disponível em: <http://www.feam.br/noticias/1/949-mapas-de-solo-do-estado-de-minas-gerais > . Acesso em: 24 abr. 2018.

26. MARQUES NETO, R.; FERNANDES, R. A.; BARRETO, J. C.; EDUARDO, C. C. A espacialidade do relevo em paisagens transformadas e sua representação: mapeamento geomorfológico da bacia do rio Paraibuna, Sudeste de Minas Gerais. In: RAEGA - o espaço geográfico em análise, Curitiba, v. 41, p. 65-81, 2017.

27. NIR, D. Man, a geomorphological agent: an introduction to Anthropic Geomorphology. Boston, Jerusalem: D. Reidel Publishing Co., Keter Publishing, 1983, 165p.

28. PASCHOAL, L. J. Estudo dos efeitos da criação de morfologias antropogênicas em área de mineração. Tese (Doutorado em Geografia). Instituto de Geociências e Ciências Exatas - Universidade Estadual Paulista. Rio Claro/SP, 2014, 177p.

29. PElOGGIA, A. U. G.; OliVEIRA, A. M. S.; OllVEIRA, A. A. O.; SILVA, E. C. N.;

D

D Revista da Associação Nacional de Pós-graduação e Pesquisa em Geografia (Anpege).

D D p.138-161, V.15, n.26, jan./mar. 2019. 
NUNES, J. O. R. Technogenic geodiversity: a proposal on the classification of artificial ground. In: Quaternary and Environmental Geosciences, v. 5, n. 1, p. 28-40, 2014.

30. PEIXOTO, M. N. O.; MELLO, E. V.; SILVA, S. M.; MOURA, J. R. S.; LOPES, C. Q. G.; SILVA, S. T.; PINTO JR., C. D. Feições tecnogênicas em Volta Redonda (RJ). In: Anais do XIII Congresso da Associação Brasileira de Estudos do Quaternário. Búzios/RJ, 2011.

31. PEREZ FILHO, A.; QUARESMA, C. C. Ação antrópica sobre as escalas temporais dos fenômenos geomorfológicos. In: Revista Brasileira de Geomorfologia, v. 12, n. 3 , p. 83-90, 2012.

32. RODRIGUES, C. Morfologia original e morfologia antropogênica na definição de unidades espaciais de planejamento urbano: exemplo da metrópole paulista. In: Revista do Departamento de Geografia - USP, v. 17, p. 101-111, 2005.

33. SZABÓ, J. Anthropogenic geomorphology: subject and system. In: SZABÓ, J.; LÓRANT, D.; LÓCZY, D. Anthropogenic geomorphology: a guide to man made landforms. London: Springer, 2010, $260 \mathrm{p}$.

34. TER-STEPANIAN, G. Did the Quinary start. In: INQUA Congress. 1983, p. 260.

35. TORRES, F. T. P. Relações entre fatores climáticos e ocorrências de incêndios florestais na cidade de Juiz de Fora (MG). In: Revista Caminhos de Geografia, v. 7, n. 18, p. 162$171,2006$.

36. TOY, T. J.; HADLEY, R. F. Geomorphology and reclamation of disturbed lands. Orlando: Academic Press Inc., 1987, 480 p.

37. VITORINO, J. C; ANDRADE, M. R. M.; PELOGGIA, A. U. G.; SAAD, A. R.; OLIVEIRA, A. M. S. Terrenos tecnogênicos do Jardim Fortaleza, bacia hidrográfica do córrego do Entulho, Guarulhos (SP): mapeamento geológico, estratigrafia, geomorfologia e arqueologia da paisagem. In: Revista Geociências - UNG-Ser, v. 15, n. 2, p. 33-60, 2016. 